\title{
Sanitation and Health: Empirical evidence for Brazilian Municipalities
}

\author{
ENLINSON MATtos* \\ Cristine Pinto* \\ LUCAS TEIXEIRA** \\ LuíS MELONI $^{* * *}$
}

\begin{abstract}
Despite the fact of being the largest economy in Latin America, piped water service coverage and sewage collection is not universal in Brazil. The relationship between access to water/sanitation and health was the objective of many studies recently. The majority of the existing work focuses on the impact of access to water and sewage, not investigating the effects of water quality and treatment. Moreover, the existing literature usually focuses on infant mortality and life expectancy indicators. Although these measures are important, they may not capture all the relevant public costs associated with health and related to hospitalizations. This paper aims at filling this gap by identifying the effects of sanitation policies on children morbidity rates by certain diseases in Brazilian municipalities.
\end{abstract}

Keywords: Sanitation policies, morbidity indicators, epidemiological transition JEL Codes: I10, I15, I18

\section{Introduction}

The role played by health in a country development path is being studied for decades by economists. While some issues, such as access to water and sanitation are not a concern in the developed world, many developing countries still struggle with them. Waterborne and respiratory diseases are examples of diseases that affect developing countries and could be solved with simple and yet cheap interventions.

Submitted on 30 April 2019; Reviewed on 26 December 2019

*EESP-FGV.

** Brazilian Central Bank

*** FEA-USP.

こenlinson.mattos@fgv.br

こlucasitenteixeira@gmail.com $\approx$ luis.meloni@gmail.com 
Despite the fact of being the largest economy in Latin America, piped water service coverage and sewage collection is far from being universal in Brazil ${ }^{1}$. The relationship between access to water/sanitation and health was the objective of many studies recently. The majority of the existing work focuses on the impact of access to water and sewage, not investigating the effects of water quality and treatment (Gamper-Rabindran, Khan, \& Timmins, 2007). ${ }^{2}$ Moreover, the existing literature usually focuses on infant mortality and life expectancy indicators. Although these measures are important, they may not capture all the relevant public costs associated with health and related to hospitalizations.

This paper aims at filling this gap by identifying the effects of sanitation policies on children morbidity rates by certain diseases in Brazilian municipalities. Socioeconomic indicators are heterogeneous among Brazilian regions. For example, according to data from the Brazilian Institute of Geography and Statistics (Instituto Brasileiro de Geografia e Estatística - IBGE) in 2013, the average educational level of individuals over 25 in southeast Brazil was 8.4 years of study, whereas the average educational level of the same age group in northeast Brazil was 6.4 years of study. Because of differences among Brazilian regions, the aim is to explore the relevant heterogeneity of developmental stages in Brazilian municipalities to identify the role of water access and quality as well as sewage sanitation on morbidity indicators.

Our results suggest that access to water is associated with a decrease in hospitalizations for dysentery and acute respiratory infections (ARI). However, we do not find significant effects of sanitation policies on hospitalizations by other causes that could be expected, such as diarrhea and hepatitis. Our paper is not the first study conducted to identify the relationship between sanitation and health in Brazil; the first was conducted by Merrick (1985). Using data from the 1970 census and National Household Sample Survey (Pesquisa Nacional por Amostra de Domicílios - PNAD) of 1976, Merrick determined that access to water had a positive impact on reducing child mortality, and maternal education was identified as the main variable contributing to reductions in mortality. This result was corroborated by Kassouf (1995). Alves and Beluzzo (2004) and Soares (2007) used data from the censuses for Brazilian municipalities between 1970 and 2000 and estimated that access to piped water reduces mortality and increases

\footnotetext{
${ }^{1}$ According to the 2000 Census, the share of households with access to piped water service coverage increased from $32.8 \%$ to $76.6 \%$ while the share with sewage collection network increased from $13.1 \%$ to $46.5 \%$ from 1970 to 2000 .

${ }^{2}$ For more on the discussion about water quality and sewage treatment, see Kremer, Leino, Miguel, and Zwane (2010).
} 
life expectancy. In contrast, Sastry and Burgard (2005) did not observe an effect of water supply expansion on diarrhea cases in northeast Brazil. This evidence led Gamper-Rabindran et al. (2007) to use quantile regression analysis to identify if the effects of sanitation policies vary with the level of income of Brazilian municipalities. The authors found that access to water has little effect on municipalities with low or high income and a much greater effect on municipalities with income close to the mean, suggesting an optimal point at which the sanitation policy may affect infant mortality.

However, these studies focused on sanitation policies according to statements from individuals (census or PNAD) with regard to water access and sewage treatment; therefore, these studies may not capture the quality of water that reaches the homes of individuals or be able to determine if sewage is collected and treated, which is a point discussed by Kremer et al. (2010). As GamperRabindran et al. (2007) point out, a more complete analysis will be to investigate not only the impact of water access on sanitation indicators, but also to estimate the impact of the quality of the water that reaches the households in Brazil on these indicators. Furthermore, these studies focus on the impact of sanitation on infant mortality and/or life expectancy indicators. Although these health measures are important, they may not capture the public costs associated with health and related to hospitalizations.

This study seeks to establish sanitation indicators and traditional access methods by quantifying water quality and sewage treatment, and it also considers as health indicators, the total morbidity caused by diseases related to water scarcity or quality. We used data from the National Sanitation Information Service (Serviço Nacional de Informações de Saneamento - SNIS) to determine water and sewage access and quality indicators. The SNIS data are supplied by utility companies in each municipality. Our study is novel because we analyzed this information along with data from the Information Technology Department of the Brazilian Public Health System (Departamento de Informática do Sistema Único de Saúde - DATASUS) to identify hospitalizations per class of disease (hepatitis A, acute respiratory infections (ARI) and dysentery per 100,000 inhabitants) as the dependent variables. Finally, we also explored differences in the epidemiological transition stages that are managed by Brazilian municipalities and may lead to heterogeneous health results in these municipalities as suggested by Gamper-Rabindran et al. (2007).

Regarding SNIS data, there are significant gaps in data, especially in the early years of our data panel. Because sanitation data are provided by utility companies, 
they may not collect these records regularly, especially if these indicators are poor or associated with previously poor indicators in the municipalities. Therefore, we propose a panel data methodology that corrects the selection bias that occurred because only certain municipalities reported sanitation information at certain points in time. To correct this selection bias, we assume that municipalities make decisions on whether to report their sanitation indicators at a certain point in time based on socioeconomic conditions and prior sanitation indicators. This municipality decision-making model is implemented with a fixed effect panel data model to estimate the relationship between sanitation indicators and health indicators. Thus, we managed to 'control' the probability of data reporting and validate our results.

Results in the international literature are similar to those found in Brazil. Barrera (1990), for example, found that maternal education and access to water can improve the health of children up to 15 years of age. Jalan and Ravallion (2001) in India, Galdo and Briceño (2005) in Ecuador, Checkley et al. (2004) in Peru, and Lee, Rosenzweig, and Pitt (1997) in Bangladesh and the Philippines found a positive effect of water access policies on the health of children. Esrey, Potash, Roberts, and Shiff (1991) reviewed several studies examining policies related to access to water and sewage and their effect on disease. In general, these policies have a positive impact on the morbidity of ascariasis, diarrhea, schistosomiasis and trachoma.

Watson (2006) estimated the positive effect of sanitation expansion in indigenous communities after 1950. The author found that a decrease in infant mortality of approximately 50\% occurred three years after the policy was adopted. The study also identified other positive effects on health such as decreased prevalence of respiratory and gastrointestinal tract diseases. Kumar and Vollmer (2013) also estimate a positive impact of improved sanitation and diarrhea for children less than 5 years of age in India. Finally, two studies estimated the effect of sanitation policies through field experiments, with Devoto, Duflo, Dupas, Pariente, and Pons (2011) and Kremer et al. (2010) finding positive results of sanitation policies on diarrhea in children up to five years of age. However, Greenstone and Hanna (2014) did not observe an effect of decreased air and water pollution on infant mortality in India.

The present article is divided into six sections. Section 2 presents data on sanitation and health in Brazil; section 3 describes the methodology developed in this study and relevance to the problem in question; section 4 describes the main results; section 5 presents evidence on Brazilian municipalities that are 
in different stages of epidemiological transition. In the last section, the main conclusions are presented.

\section{Sanitation and Health in Brazil}

\subsection{Sanitation}

The first policy adopted by the Brazilian government to improve basic sanitation throughout the country dates from the 1960 and 1970 decades, when the National Housing Bank (Banco Nacional de Habitação - BNH) and the National Sanitation Plan (Plano Nacional de Saneamento - Planasa), were established. In the 1990 decade, several federal programs aiming at increasing sanitation services' quality and reducing access inequality were adopted. ${ }^{3}$

The most significant legal changes, however, were observed in the years the 2000s, when the National Water Agency (Agência Nacional de Águas - ANA), a federal entity that implements the National Policy of Water Resources and coordinates the National Water Resources Management System, was created, and when the act 9,984, that states that all municipalities must prepare local sanitation plans by 2013 under penalty of a reduction of federal funds, was passed. It was in that period that Brazil signed United Nations' Millennium Development Goals, which requires it reduce infant mortality rate by two thirds and increase access to potable water by one half by 2015. The main consequence of these legal efforts is observed in data from demographic censuses from 1970 to 2000. The share of households with access to piped water service coverage increased from $32.8 \%$ to $76.6 \%$ while the share with sewage collection network increased from $13.1 \%$ to $46.5 \%$ in this period.

Despite such improvements in services, access is still unequal. Water and sanitation access data in 2000 for the micro-regions of Brazil are presented in figures Figure 1(a) and Figure 1(b). These figures shows a concentration of low indicators in the north and northeast regions despite improvements of the mean indicator. Municipalities are divided into three groups: higher access quantiles are darker, intermediary access quantiles are grey, and the worst access quantiles are lighter.

We observed that a regional dispersion pattern remained. The micro-regions of central-south Brazil exhibited higher sanitation indices than those in north-

\footnotetext{
${ }^{3}$ For instance, the Modernization of the Sanitation Sector Program (Programa de Modernização do Setor de Saneamento - PMSS), that provided technical support for the adoption of policies in the sector, dates from 1995. The Concessions Act, that allows the private sector to provide sanitation services, dates from 1996.
} 
Figure 1. Access to a general network of piped water (left) and sewage (right) among Brazilian micro-regions in 2000; separated into three quantile groups.

(a)

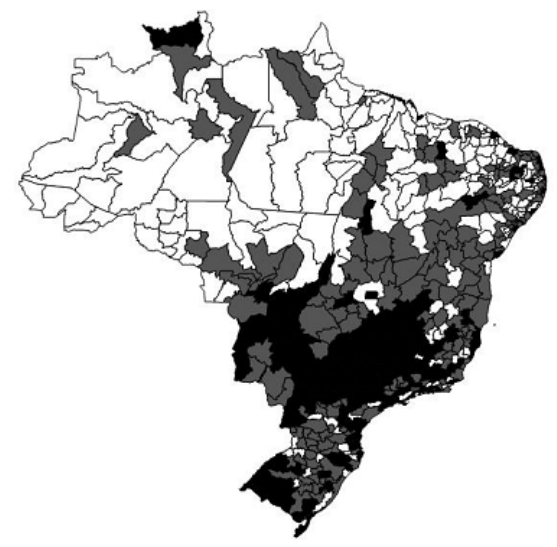

(b)

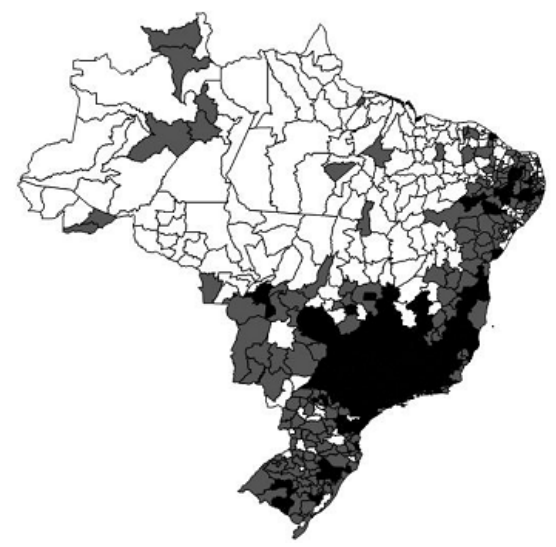

Source: 2000 Census. Software: IpeaGEO.

northeast Brazil. In all regions of the country, water access coverage is higher than sewage network coverage.

\subsection{Health}

In the 1970 census, 123.2 deaths occurred in children below one year of age per 1000 live births. This rate dropped to 83.2, 44.7 and 30.6 deaths per live births in the 1980, 1991 and 2000 censuses, respectively. Figures 2(a) and 2(b) show the distribution of infant mortality rates calculated from the number of infant deaths (up to one year of age) per 1000 live births for the Brazilian micro-regions in 2000 and 2010, respectively. In 2000, a limited number of micro-regions had infant mortality rates lower than 16 deaths per 1000 live births (lighter areas); however, by 2010, micro-regions with mortality rates lower than 16 deaths per 1000 live births had spread within the center of the country, whereas micro-regions with mortality rates higher than 22 deaths per 1000 live births (darker areas) had decreased.

A decrease in mortality rates up to 16 per 1000 live births is concentrated in central-south Brazil. In the central-north and northeast Brazil mesoregions, although infant mortality rates decreased compared with the rate in 2000 , the infant mortality rates are generally over 20 per 1000 live births.

This regional discrepancy appears to indicate heterogeneity among Brazilian cities in relation to the country's epidemiological transition. Sanders, Fuhrer, 
Figure 2. Mortality rate in children aged up to one year per 1000 live births among Brazilian micro-regions in 2000 (left) and 2010 (right) separated per quantile group.

(a)

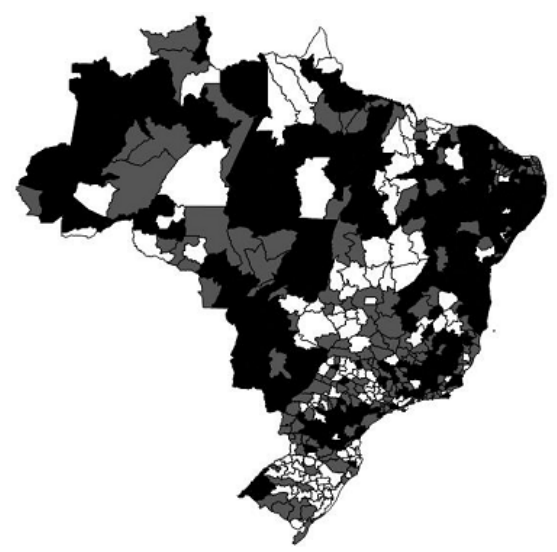

(b)

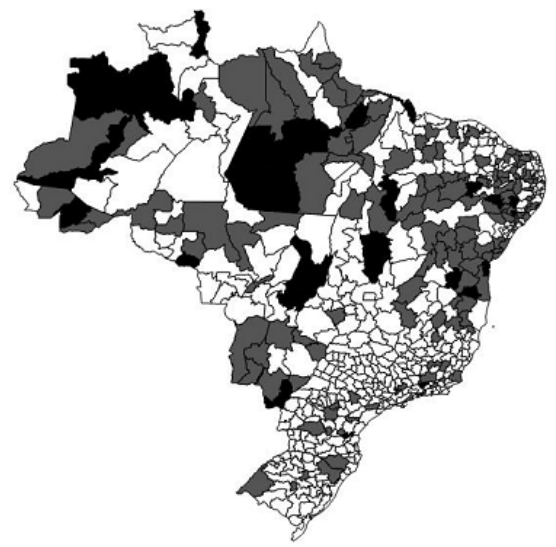

Source: DATASUS. Prepared by the authors.

Johnson, and Riddle (2008) stated that the epidemiological transition (Omran's Theory), a phenomenon in which countries transition from acquiring infectious diseases to degenerative diseases, can differ depending on the level of development of the countries. Their study found that with the establishment of sanitation and hygiene practices, vaccines and antibiotics, countries with improved economic conditions can substantially reduce these infectious diseases. A possible consequence of this type of policy would be an increase in the percentage of degenerative diseases in these statistics.

The economic heterogeneity and size of Brazil provide an excellent opportunity to investigate, at least partially, Omran's Theory of Epidemiologic Transition, particularly because the health sector is federally regulated and the same incentives are provided to all municipalities. Thus, all federal units are governed under the same rules, and the only differences among municipalities are their development and health indicators. However, a preliminary investigation of these diseases is necessary. Figure 3 presents the spatial pattern of mortality caused by infectious diseases (regions still in epidemiological transition) compared with degenerative diseases (tumors).

These maps show that less developed municipalities that have lower indicators of access to water and sanitation, such as those in the north region and part of the northeast region, have the highest rates of mortality from infectious diseasesdarker areas in Figure 3(a). Deaths from degenerative diseases (tumors) are 
Figure 3. Mortality from infectious diseases (left) and tumors (right) presented as a ratio of the total mortality among Brazilian micro-regions in 2000.

(a)

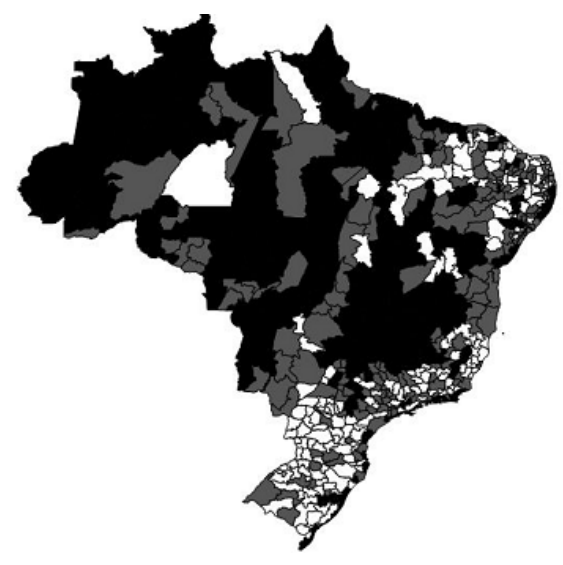

(b)

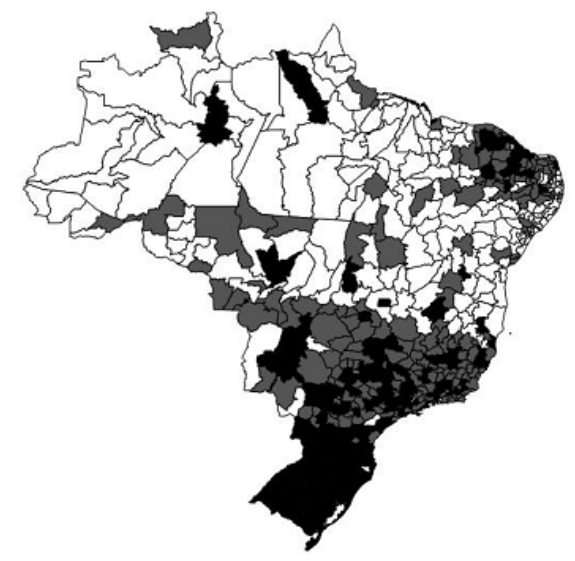

Source: DATASUS. Software: IpeaGEO.

concentrated in central-south Brazil, which is the most developed region- darker areas in Figure 3(b). These maps reinforce, at least preliminarily, the hypothesis that Brazil is heterogeneous in terms of development and has regions at different stages of epidemiological transition. In the next section, we describe the data and empirical strategies used to estimate the relationship between sanitation and health.

\subsection{Database and Descriptive Analysis}

This study presents a novel use of two databases related to sanitation and health. The SNIS is a database maintained by the federal government's Ministry of the Cities, and it contains information on water and sewage providers in each municipality. In this study, we used SNIS data from 2003 to 2010. The rates of access to water and sewage were represented by the percentage of the total population in a given municipality that has access to water, percentage of the total population of a given municipality that has access to sewage collection and percentage of the population receiving sewage collection that has access to sewage treatment. ${ }^{4}$ In addition, the method established here calculates service inefficiency as the percentage of losses that occur during water distribution. Finally, we used the indices of non-standard turbidity analyses, non-standard

${ }^{4}$ In most cases, the sanitation company considers 1 as "collection services available" and 0 as "no collection services available," which generates concentration of this variable at $0 \%$ or $100 \%$. 
total coliforms analyses and non-standard residual chlorine analyses as water quality measures.

The number of municipalities that report information to SNIS varies markedly from indicator to indicator. In 2010, a total of 4,935 municipalities among 5,564 reported information on water service, whereas only 1,632 municipalities reported information on sewage collection. The sewage system in Brazil is less developed than the water access system. In certain Brazilian municipalities, the utility company only provides services related to water and is not involved in sewage collection or treatment. In addition, the number of municipalities that report information varies over time. For example, approximately 1,170 municipalities reported information on sewage collection in 2006, whereas only 4,300 answered questions related to water access.

Health indicators are extracted from the database of the Public Health System (Sistema Único de Saúde - SUS), which is known as DATASUS. Using this database, we obtained the rates of hospitalizations that will be used as health indicators in this study. The indicators were assessed per diseases. The infant mortality indicator is frequently used in the literature to determine the impact of basic sanitation. In this study, we are interested at the impact of sanitation policies on hospitalizations of specific water-based diseases.

In turn, the lack of sewage collection and treatment increases the frequency of contact with sewage, which increases the incidence of disease. Galdo and Briceño (2005) list four classes of disease that are directly or indirectly acquired from water, including diseases caused by poor water quality that is contaminated by sewage; diseases related to insufficient water volume for personal hygiene; diseases caused by waterborne organisms, such as schistosomiasis and worms; and diseases transmitted by insects that breed in water and polluted environments. These diseases may cause hospitalizations and can result in death.

Children are more susceptible to the first two classes of diseases as a result of their greater likelihood of coming into contact with sewage compared with adults and because they suffer more as a result of insufficient water volume. These effects can be exacerbated in children, especially children under five years of age because they have a greater likelihood of complications compared with adults.

In this article, we use the number of hospitalizations for certain diseases per 100,000 inhabitants as a health indicator. The diseases are those related to sanitation quality and infectious diseases that mainly affect children, including 
diarrhea, dysentery, hepatitis, and ARI. ${ }^{5}$ These diseases are related to contaminated water without treatment, and they can be established by our quality indicators. In addition, these diseases may also be related to a lack of water (access) for personal hygiene.

We also used other variables as controls in our model. The population of each Brazilian municipality was estimated in July $1^{\text {st }}$ of each year by the IBGE for the period 2003 to 2006 and the years 2008 and 2009. In 2007, the IBGE performed a population count, and in 2010, they performed a demographic census. The gross domestic product (GDP) of each municipality was also calculated by the IBGE. ${ }^{6}$ The educational level of the municipality was determined by the ratio of children between zero and six years of age who were enrolled in daycares or preschools, which is constructed with data from school censuses from 2003 to 2011. In addition, we consider the rate of vaccination coverage of each municipality and the percentage of the population served by the Family Health Program (Programa Saúde da Família). Both datasets are extracted from DATASUS.

Table 1 summarizes the descriptive statistics of all variables used in the study, which are grouped from 2003 to 2010 . The mean number of hospitalizations for ARI is high (11.36 per 100,000 inhabitants) in relation to hepatitis (0.07) or dysentery (2.6). Approximately $65 \%$ of the municipalities had water service from 2003 to 2010 , and approximately $36 \%$ had sewage treatment. The vaccination coverage is $81 \%$ on average.

Figures 4 and 5 present changes in water and sewage indicators for each Brazilian region. These graphs indicate that water service is much lower in the north and northeast regions of Brazil compared with other Brazilian regions. Sewage collection and treatment are much higher in southeast Brazil compared with other regions. These graphs also indicate limited variation in water and sanitation access indicators over time. The non-standard chlorine index is much higher in the north and northeast regions compared with the rest of Brazil.

Figure 6 presents changes in the hospitalizations per type of disease. Hospitalizations for diarrhea, dysentery and hepatitis are higher in the north and northeast regions, whereas hospitalizations for ARI are higher in southern Brazil.

\footnotetext{
${ }^{5}$ In a preliminary version of the study, we considered the following health indicators: hospitalizations for diseases such as tuberculosis and tetanus. The results are available upon request to the authors.

${ }^{6}$ We used the logarithm of the population in our models. According to the IBGE 2008, the GDP is decreased by an implicit deflator of the national GDP and is calculated according to the distribution of added value of the main local economic activities.
} 


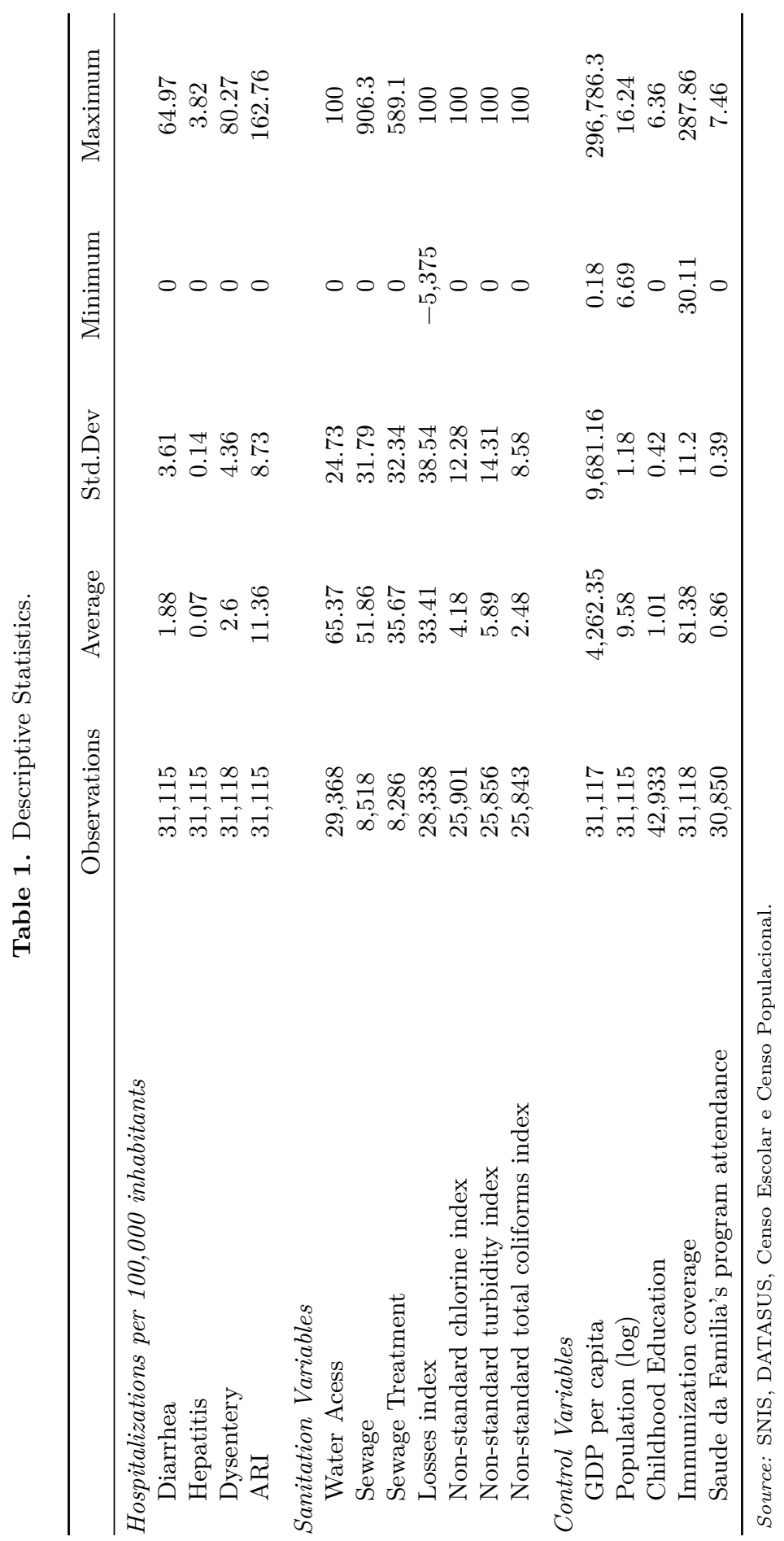


Water Access

90

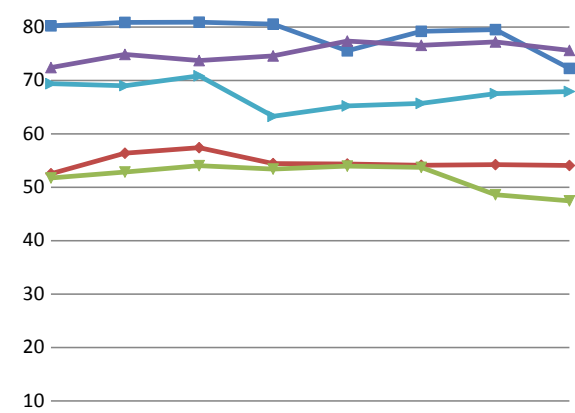

$\begin{array}{llllllll}2003 & 2004 & 2005 & 2006 & 2007 & 2008 & 2009 & 2010\end{array}$

$\longrightarrow$ Central-West $\longrightarrow$ Northeast $\rightleftharpoons$ North

$\rightarrow$ Southeast $\rightarrow$ South

\section{Sewage treatment}

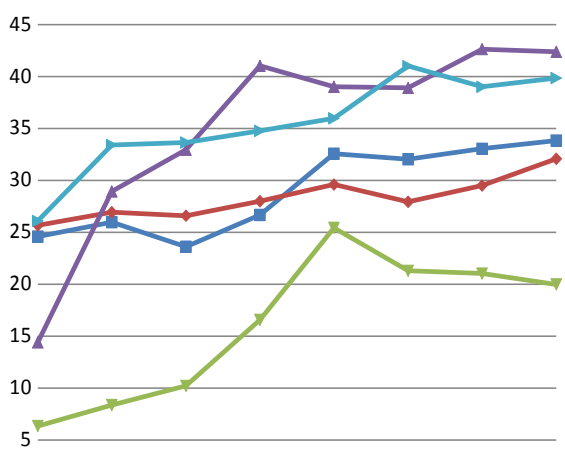

$\begin{array}{llllllll}0 & & & & & & & \end{array}$
Sewage

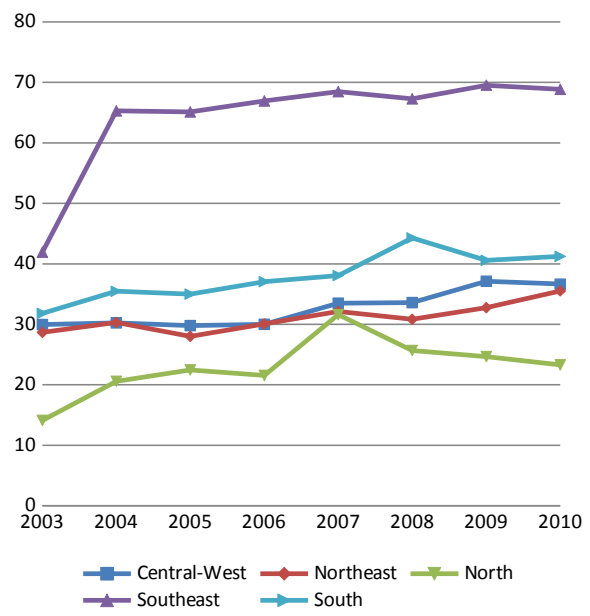

Losses index

60

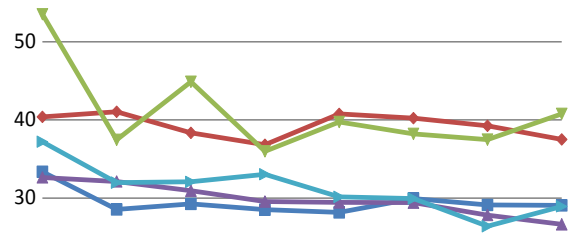

20

10

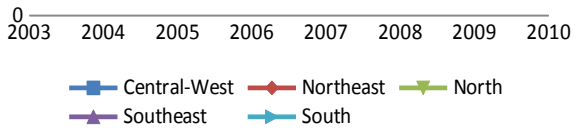

Figure 4. Evolution of Water and Sewage Indicators per Brazilian Region. 
Non standard clorine index

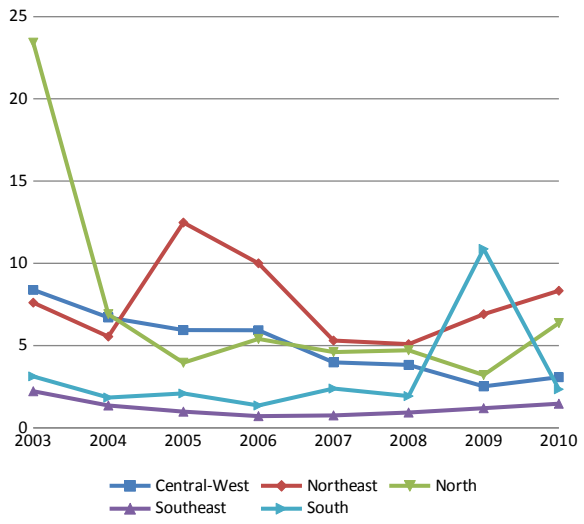

Non standard turbidity index

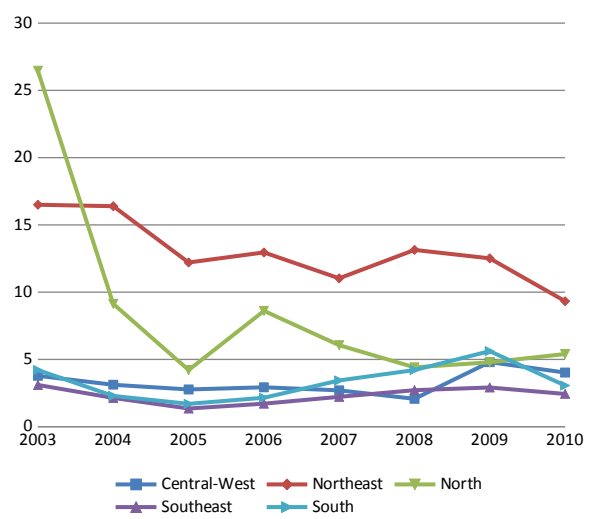

Non standard total coliforms index

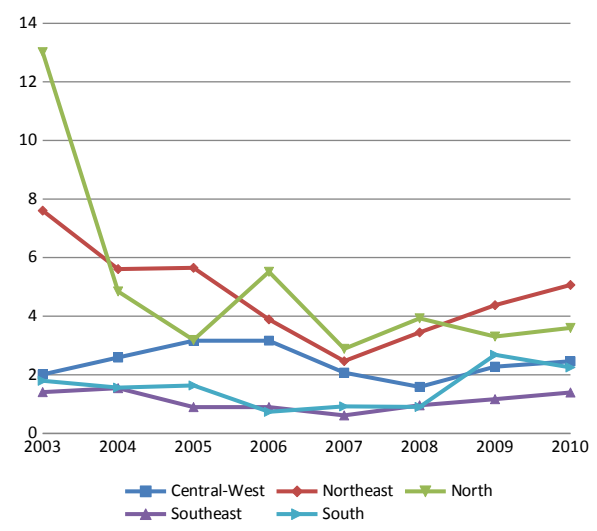

Figure 5. Evolution of Water Quality Indicators per Brazilian Region.. 
Morbidity - Diarrhoea

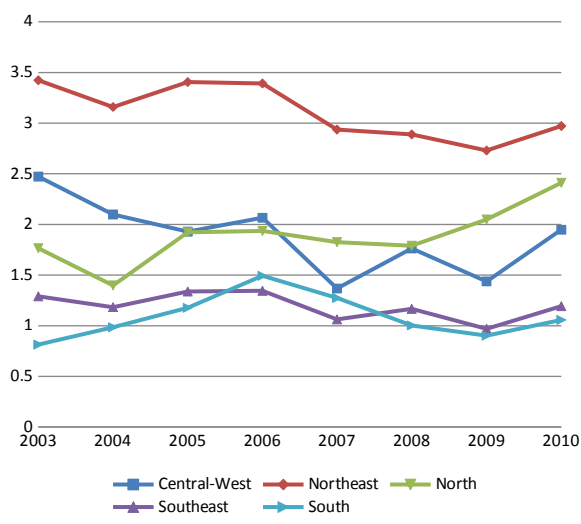

Morbidity - Hepatitis
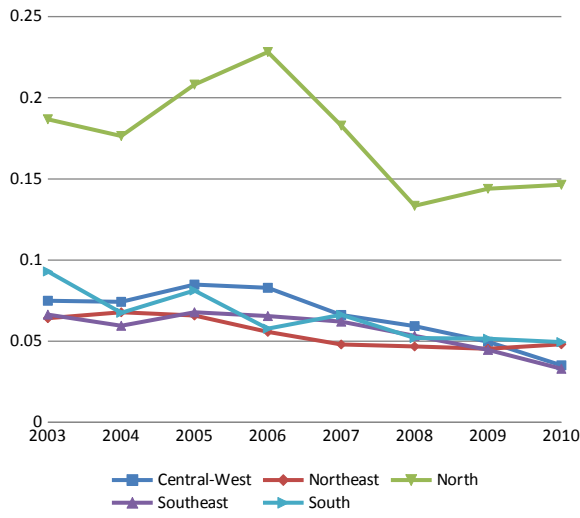

Morbidity - Dysentery

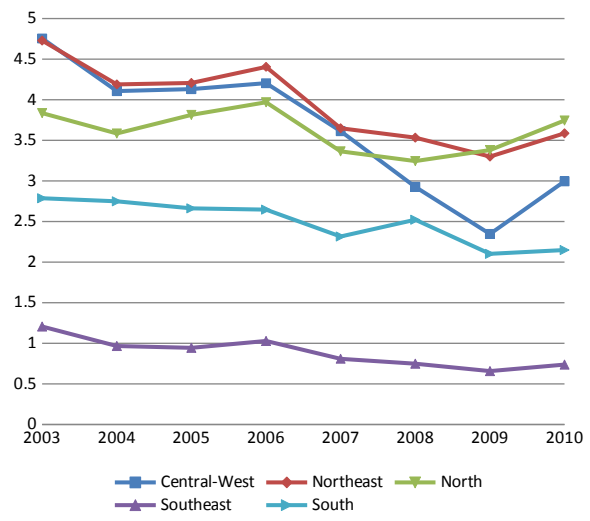

Morbidity - IRA

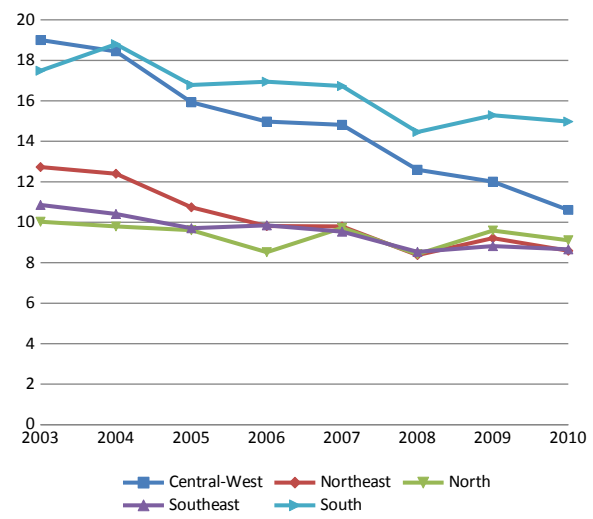

Figure 6. Evolution of Hospitalizations per Disease per Brazilian Region.

Most of the ARI hospitalizations in the south region are associated with the colder climate of the area. All of the panels emphasize the heterogeneous evolution of health and sanitation indicators in the Brazilian regions.

\section{Empirical Strategy}

To estimate the effect of sanitation indicators on hospitalizations by disease, we used a panel data model with fixed effects. In this model, we have included past health indicators. As emphasized by several authors (Watson, 2006 and ?), changes in sanitation infrastructure affect health variables during the period 
of change as well as future indicators. In this article, we used the following fixed-effect panel model:

$$
\begin{aligned}
\text { IndHealth }_{i t}= & \beta_{0}+\beta_{1} \text { IndWater }_{i t}+\beta_{2} \text { IndWater }_{i, t-1}+\beta_{3} \text { IndWater }_{i, t-2} \\
& +\alpha \text { Controls }_{i t}+a_{i}+t \eta_{\mathrm{CO}}+t \eta_{\mathrm{N}}+t \eta_{\mathrm{NO}}+t \eta_{\mathrm{S}}+t \eta_{\mathrm{SU}}+u_{i t},
\end{aligned}
$$

where IndHealth $_{i t}$ represents health indicators for municipality $i$ in period $t$; IndWater represents all variables related to water access, water quality, sewage treatment and collection; and Controls represents other model explanatory variables. In addition, a fixed effect was included in the model for each municipality $\left(a_{i}\right)$, and a non-linear trend was included per Brazilian region. This trend is formed by the interaction between a binary variable that is equal to 1 if municipality $i$ is in region $j\left(\eta_{j}\right)$ and a linear trend $(t)$. These trends can capture different trajectories of health variables among Brazilian regions. As previously mentioned, the vector of controls includes the logarithm of the population of each municipality, GDP per capita of each municipality, percentage of the population zero to six years of age that is enrolled in early childhood education, degree of vaccination coverage in the municipality and percentage of the population served by the family health program. In addition, we included sanitation variables (IndWater) for the previous period $(t-1)$ and two previous periods $(t-2)$.

Because the number of municipalities that report information to the SNIS increases over time, if we only estimate the panel for municipalities that reported information throughout the entire period from 2003 to 2008, a large number of municipalities will be left out of the estimation. If these municipalities had the worst sanitation infrastructure at the beginning of the period, the results will be biased. To verify if panel attrition is related to prior variables in the municipalities and determine if such attrition would generate a bias in our results, two attrition tests used in the literature were implemented here. The description of the tests and the tables with the results are in Appendix A. The results of both tests indicate that attrition is not random and show that it is related to the population size and sewage collection in the previous period.

To correct for bias in the results generated by attrition, we used a model for municipality decision-making related to reporting information on a variable to the SNIS over time. The likelihood of the municipality reporting information to the SNIS in period $t$ will be a function of the sanitation indicators in past periods and lagged explanatory variables. Define $s_{i t}$ as an indicator variable that equals one if municipality $i$ reports information on period $t$. The municipality $i$ 
report information depending on the past sanitation indicators $\left(w_{i t}\right)$ and an unobservable term $\left(\varpi_{i t}\right)$. The function indicating whether the municipality is included in the SNIS database is as follows:

$$
s_{i t}= \begin{cases}1 & \text { if } \varpi_{i t}>-\varphi_{0}-\varphi_{i t} w_{i t} \\ 0 & \text { if } \varpi_{i t} \leq-\varphi_{0}-\varphi_{i t} w_{i t}\end{cases}
$$

where $w_{i t}=\left[\right.$ IndWater $_{i, t-1}$, IndWater $_{i, t-2}$, Controls $_{i, t-1}$, Controls $\left._{i, t-2}\right]$, and $t=$ 2005,2010 .

In addition, we assume that $\left\{\omega_{i t} \Delta x_{i t}, w_{i t}\right\}$ is a non-observed variable that has a normal distribution with a mean of zero and variance of one.

In this corrected model, model (1) is used in the first difference form:

$$
\begin{aligned}
\Delta \text { IndHealth }_{i t}=\beta \Delta x_{i t}+\Delta t \eta_{\mathrm{CO}}+\Delta t \eta_{\mathrm{N}}+\Delta t \eta_{\mathrm{NO}}+\Delta t \eta_{\mathrm{S}} & \\
& +\Delta t \eta_{\mathrm{SU}}+\Delta u_{i t},
\end{aligned}
$$

where

$$
\Delta x_{i t}=\left[\Delta \text { IndWater }_{i t}, \Delta \text { IndWater }_{i, t-1}, \Delta \text { IndWater }_{i, t-2}, \Delta \text { Controls }_{i t}\right]
$$

If a municipality did not report the information in $t-1$, then its probability of reporting the information in $t$ is not affected, and the conditional expectation of the error of this equation will depend on the error in the probability of the municipality reporting information in $t$ and $t-1$, and it will not depend on the interaction between these two errors:

$$
\mathbb{E}\left[\Delta u_{i t} \mid \Delta x_{i t}, w_{i t}, s_{i t}=1, s_{i, t-1}=1\right]=\rho_{1} \varpi_{i t}+\rho_{2} \varpi_{i, t-1} .
$$

Using this equation and the model in its first difference form, we obtained the following expression for conditional expectations of variation among health indicators:

$$
\begin{aligned}
\mathbb{E}\left[\Delta \text { IndHealth }_{i t} \mid \Delta x_{i t}, w_{i t}, s_{i t}\right. & \left.=1, s_{i, t-1}=1\right]=\beta \Delta x_{i t}+\Delta \delta_{t} \\
+\rho_{1} \mathbb{E}\left[\varpi_{i t} \mid \varpi_{i t}>-\varphi_{0}-\varphi_{i t} w_{i t}\right] & \\
& +\rho_{2} \mathbb{E}\left[\varpi_{i, t-1} \mid \varpi_{i, t-1}>-\varphi_{0}-\varphi_{i t} w_{i, t-1}\right] .
\end{aligned}
$$

Using the normal distribution properties, the following linear model is 
established:

$$
\begin{aligned}
\text { IndHealth }_{i t}=\beta \Delta x_{i t}+\Delta t \eta_{\mathrm{CO}}+\Delta t \eta_{\mathrm{N}} & +\Delta t \eta_{\mathrm{NO}}+\Delta t \eta_{\mathrm{S}}+\Delta t \eta_{\mathrm{SU}} \\
& +\rho_{1} \lambda\left(\delta w_{i t}\right)+\rho_{2} \lambda\left(\delta w_{i, t-1}\right)+\xi_{i t},
\end{aligned}
$$

where

$$
\lambda\left(\delta w_{i t}\right)=\frac{\varphi\left(\delta w_{i t}\right)}{\Phi\left(\delta w_{i t}\right)}, \quad \text { and } \quad \lambda\left(\delta w_{i, t-1}\right)=\frac{\varphi\left(\delta w_{i, t-1}\right)}{\Phi\left(\delta w_{i, t-1}\right)}
$$

represent the functions that control the bias caused by the municipalities not reporting information to the SNIS over time; and $\xi_{i t}$ is the unobservable term in this equation.

To estimate this final model, we used a two-step procedure. In the first step, we estimated a probit model that relates the indicator of municipality $i$ reporting information in period $t\left(s_{i t}\right)$ as vector $w_{i t}$. In this first step, we estimated the correction terms $\lambda\left(\delta w_{i t}\right)$ and $\lambda\left(\delta w_{i, t-1}\right)$. In the second step, we estimated a linear regression that relates variation of health indicators with variations of explanatory variables, including variation of the trends per region and correction terms. The standard errors are calculated by bootstrap. In the following section, we will present the results obtained for the model with endogeneity-uncorrected data as well as the model estimated by this two-step procedure.

\section{Mean Effect of Sanitation on Health}

In this section, we present the results of the impact of sanitation policies on the hospitalization by diseases in Brazil. In all tables, the first column includes the fixed effect model without the attrition correction, and in the second column, we present the results of the model with the bias correction for attrition. These models usually have the highest explanatory power and can include variations of sanitation policies lagged by up to two periods, which is similar to the model of Watson (2006). We focused our analysis on variables with at least a $5 \%$ significance level. In Appendix B, we present the results of the first step of this procedure, which estimated the factors related to the probability of the municipality reporting information to the SNIS in period $t$.

Most of the results of the model without the attrition correction (odd columns) has the same sign of the results with the correction. Since we have evidence that attrition is not random in our data, we focus on the results with correction (even columns).

Evidence that water access policies are associated with hospitalizations 
caused by diarrhea was not obtained here, which is a similar result to that of Sastry and Burgard (2005) and inconsistent with the results of Kremer et al. (2010) for Kenya and Kumar and Vollmer (2013) for India, and these policies are not associated with hospitalizations caused by hepatitis either. Hepatitis is an inflammation of the liver, which has several causes. Hepatitis A and E are transmitted by contaminated water and food, and this indicates a lack of sanitation caused by a lack of sewage treatment or lack of piped water. Because symptoms are only detected one month after contamination, the severity may increase, especially in children. A result that is corroborating by the literature is that the incidence of vaccination reduces morbidity caused by diarrhea. Contrary to the literature, we found a positive effect of sewage access in the past on hospitalizations by diarrhea in the current period. This result can be related to policies that provide poorly sewerage in the municipality, and after a period, the municipality is back to the situation of no sewage. In order to investigate the mechanism of these impact, we will need more detail data about sewage coverage.

One explanation by this lack of effect of sanitation policies on hospitalization by diarrhea and Hepatitis in Brazil is that in the 2000s, access to water was already practically universal in Brazil and access to sanitation and sewage treatment improved slightly during the study period. In the descriptive data analysis (figures 4 and 5), we show that variation in access to water and sanitation was limited, whereas access to sewage treatment increased considerably in Brazilian regions. It is important to emphasize that this sewage treatment indicator represents the population percentage that has access to sewage. Thus, these graphs indicate that variations in sanitation indicators from 2003 to 2010 were not large and these small variations associated with a not very high incidence of these diseases may be a possible explanation for the modest effects.

Another possible explanation is that sanitation effects differ among the Brazilian municipalities depending on their developmental stage. When we obtained the effect of sanitation for Brazil as a whole, we did not observe a high effect that should have occurred in municipalities with low health indicators. We investigate this hypothesis in the other section of the article.

One interesting result is that sanitation policies do not have an important effect on hospitalization by diarrhea, but immunization policies matter. This finding corroborates some medical studies (Lilford et al., 2017) that advocate that universal childhood vaccination program could be a good strategy to control the spread of these diseases in Brazil. 
However, sanitation policies have an important impact on the disease that is responsible for the great number of hospitalizations among children under five, ARI. Access to water appears to be important for reducing hospitalizations caused by dysentery and ARI. Dysentery infections are spread by contaminated hands, food, and water and are related to poor sanitation quality. The high spread of contamination via the hands increases the risk of the disease being diagnosed in children. Access to water and sewage treatment are extremely important factors for reducing hospitalizations caused by dysentery in the current period. We estimate that an increase of one percentage point in access to water and sewage treatment would reduce hospitalizations caused by dysentery by 0.033 and 0.0102 , respectively, per 100,000 inhabitants over the same period, which indicates that a contemporaneous increase of 1 standard deviation in access to water and sewage treatment would decreases hospitalizations for dysentery by 0.19 and 0.08 standard deviations. Access to water is also associated with a reduction of 0.08 standard deviations in these hospitalizations in two subsequent periods. Finally, a different trend for this hospitalization indicator is observed in the north region, and our control functions used to correct selection bias are significant.

ARIs have a particularly strong effect on child populations in urban areas with poor hygiene, and they cause morbidity related to bronchiolitis, pneumonia, runny nose and adenoiditis, which affect the respiratory capacity. Access to sanitation can reduce these infection cases while improving the quality of hygiene of households. We found that water access policies had a strong ability to reduce hospitalizations related to ARI. In particular, we estimated that an increase of 1 standard deviation in access to water reduces hospitalizations for ARI within the same period by 0.11 standard deviations, and there is a corresponding increase of 0.10 standard deviations in the reduction of hospitalizations for ARI among the t- 1 results. Thus, we observed a lagged effect of sanitation policy on this health indicator. The increase of one percentage point in access to infant education reduced hospitalizations for ARI by 1.2 per 100,000 inhabitants. GDP is positively associated with these hospitalizations and most likely indicates the municipality's development. This result reinforces the evidence showing that developed municipalities (higher per capita income and improved access to health policies) have increased hospitalizations for ARI, which is most likely because of higher environmental pollution levels. We also found evidence of different evolution trends of these hospitalizations among Brazilian regions. However, our sample bias corrected model was not significant in this case.

This result indicate that sanitation policies have a significant and positive 
impact in decreasing the hospitalization of the disease that is the most common cause of death in children under five in development countries, ARI. In addition, we find no effect of sanitation policies on diarrhea (the second most common disease among children under five), but that immunization coverage is important for this disease. These findings are important to target health problems that want to control for the spread of contaminated water based diseases in Brazil. Our results indicate that sanitation programs are important to control some of these diseases, but these policies may need to be combined with other ones, like vaccine coverage. These results maybe relate to the epidemiological stage of each municipality in Brazil. It could be the case that some municipalities have universal vaccine coverage and sanitation policies, and water based diseases like diarrhea is not a concern, while others municipalities need to invest in such policies to prevent hospitalizations and deaths by such diseases. In the next section, we estimate a version o model in which we allow that the sanitation policies have different effect on municipalities at different development stages.

\section{Epidemiological Transition}

In this section, we modified the model presented in section 4 to allow for different effects of the sanitation variables on health indicators depending on the epidemiological transition stage of the Brazilian municipality. Therefore, we ordered the municipalities according to each health indicator and created three groups for each indicator. The first group contains the municipalities in the first quartile of the distribution, or the municipalities among the highest $25 \%$ for health indicators in that year; the second group corresponds to the $2^{\text {nd }}$ quartile; and the last group contains municipalities that are among the lowest $25 \%$ for health indicators in that year. We observed that municipalities rated as having the $25 \%$ lowest health indicators in one year could have in a different ranking in another year. ${ }^{7}$ Thus, we used sanitation indicators interacting with binary variables as explanatory variables in this model to indicate whether municipalities belong to each of the groups. Hence, the effect of sanitation on health may be different for each of these four groups. The results of this new exercise are listed in Table $4 .^{8}$

\footnotetext{
7 This model is referred to as variable ranking. The results for the municipalities with fixed epidemiological order in all models are given in Appendix C.

8 The estimated models in this section also include the same control variables as the previous models (population, GDP, early childhood education, and Family Health Program attendance), regional trends and control functions. Because we are interested in discussing the epidemiological transition in this section, we omitted the results related to these explanatory variables.
} 


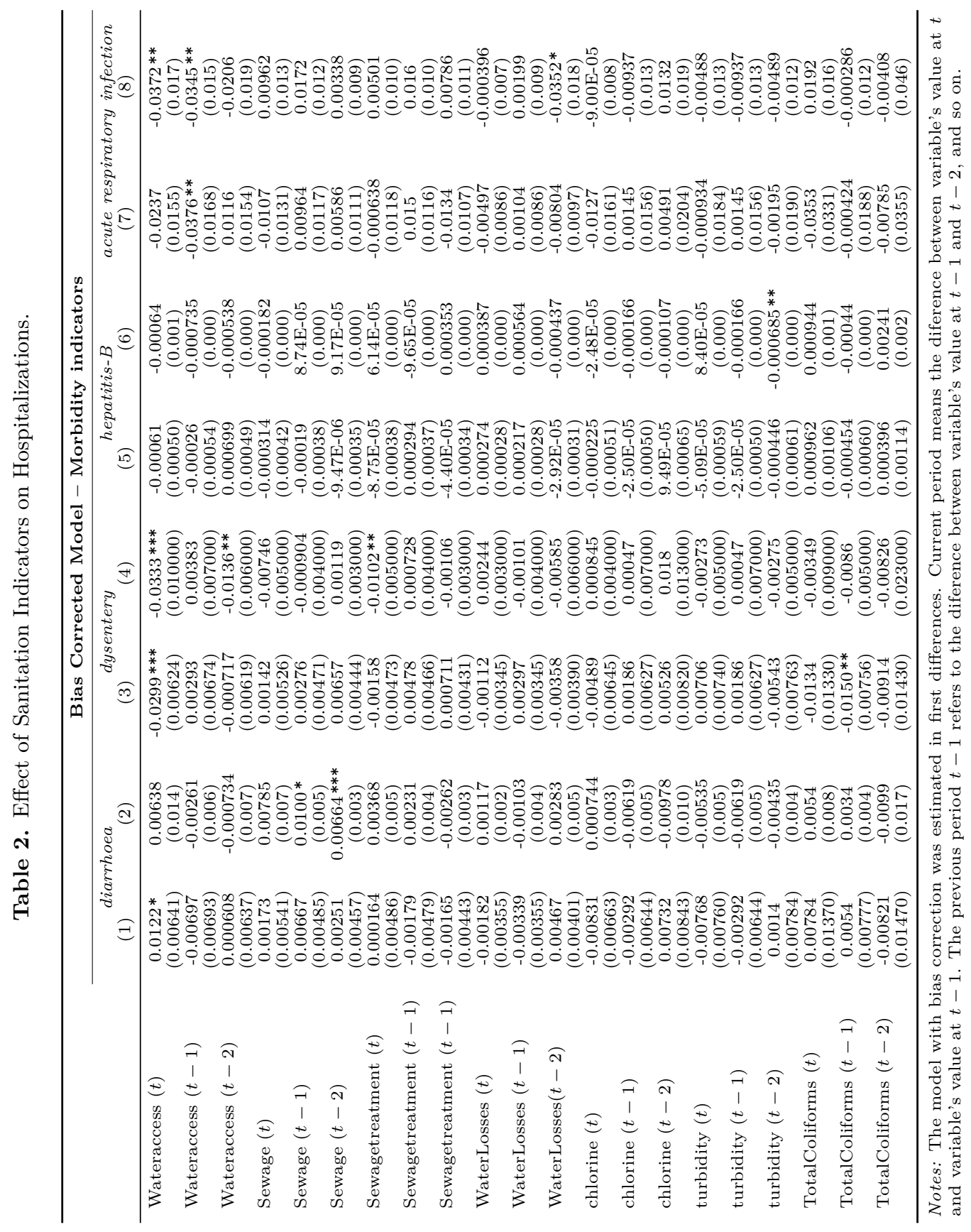




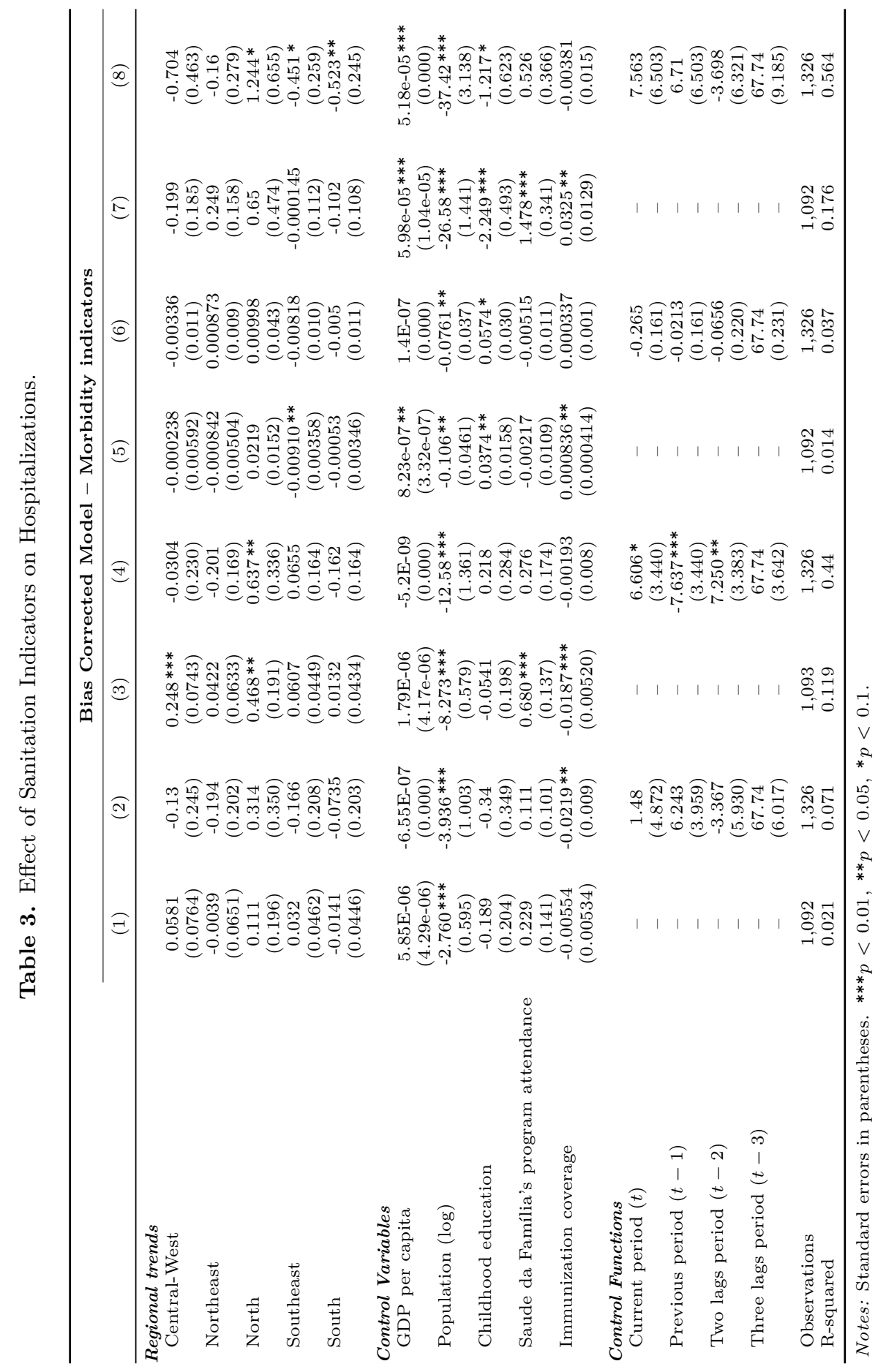


The effects of sanitation policies on diseases by quartiles do not present evidence in favor of epidemiological transition. Similar to the results for the mean, we observed that only hospitalizations for certain diseases are systematically affected by sanitation policies. However, evidence is not available to support a greater effect of sanitation on hospitalizations for diseases for the $25 \%$ worst municipalities. For example, for hospitalizations by ARI and by dysentery, the impact of water access is higher for the municipalities at the median. So we cannot confirm that the heterogeneity among Brazilian municipalities is the explanation for the no impact of sanitation policies on hospitalizations by diarrhea and hepatitis.

These new results reinforce the policy message that in Brazil sanitation policies may not be the solution for the spread of all the water based diseases, and other policies can be important for this purpose like vaccine coverage.

It is important to emphasize that all the results in the paper need to be analyze with caution. We believe that we improve the methodology usually used to estimate the impact of sanitation policies on health indication by using a fixed effect panel data with attrition correction. Although this methodology controls for non-observable characteristics of the municipalities that could affect the sanitation policies and health indicators, our estimate may be underestimate the effect of sanitation on hospitalization by specific diseases because of measurement error problems and spillover effects. For example, if the hospitalizations by diseases are underreported in the municipalities that have the lowest socioeconomic conditions and the worst access to water and sewage, the impact of sanitation on these health indicators may be underestimated. We are dealing with infectious diseases and if children in one municipality may benefitted indirectly by sanitation policies in municipalities in the neighborhood, there are positive spillovers of sanitation policies that our estimates are not taking into account. So, the effect of sanitation indication on diarrhea hospitalization may be underestimated.

\section{Conclusion}

This article identifies the effects of sanitation policies on water-borne diseases for Brazilian municipalities. In addition, it explores the heterogeneity among developmental stages of Brazilian municipalities to identify the role of water access and quality and sewage sanitation on morbidity indicators in these municipalities. Using a fixed effect model that controls for bias resulting from missing data caused by a lack of sanitation information for several Brazilian 
municipalities, we found evidence that access to water and sewage treatment reduce hospitalizations because of dysentery, and a strong effect was observed for water access policies on the reduction of hospitalizations for ARI. It is important to emphasize that ARI is most common cause of hospitalization and deaths among children under five years of age. However, we found no evidence that sanitation policies are associated with hospitalizations caused by diarrhea or hepatitis. One result that corroborates the evidence in the literature is that vaccine coverage decreases the hospitalizations by diarrhea.

We do not find evidence that support the hypothesis that Brazilian municipalities are in different epidemiological transition stages. If the municipalities in Brazil are in different stages of epidemiological transition, we expect that in municipalities with highest level of hospitalization by diseases, the impact of sanitation indicators are higher than the impact on the other municipalities.

Our article sends an important policy message. Sanitation policies are important public health intervention to reduce the spread of important diseases like ARI, however after an almost universal access to water, policies toward access to water and sewage do not have a statistically significant effect on other water-based diseases, like diarrhea. For this disease, vaccine coverage seems an important intervention. The message is that to avoid the spread of water based diseases in Brazil, sanitation policies and vaccine coverages are important. In further research, it will be interested to do cost-benefit analysis of these policies and estimate the importance of these policies in countries with different stages of development.

\section{References}

Alves, D., \& Beluzzo, W. (2004). Infant mortality and child health in Brazil. Economics and Human Biology, 2(3), 391-410.

Barrera, A. (1990). The role of maternal schooling and its interaction with public health programs in child health production. Journal of Development Economics, 32, 69-91.

Becketti, S., Gould, W., Lillard, L., \& Welch, F. (1988). The panel study of income dynamics after fourteen years: An evaluation. Journal of Labor Economics, 6(4), 472-492. https://www.jstor.org/stable/2534852

Checkley, W., Gilman, R. H., Black, R. E., Epstein, L. D., Cabrera, L., Sterling, C. R., \& Moulton, L. H. (2004). Effect of water and sanitation on childhood health in a poor Peruvian peri-urban community. The Lancet, 363, 112-18.

Devoto, F., Duflo, E., Dupas, P., Pariente, W., \& Pons, V. (2011, April). Happiness on tap: Piped water adoption in urban Morroco (Working Paper No. 16933). NBER. http://dx.doi.org/10.3386/w16933 
Esrey, S., Potash, J., Roberts, L., \& Shiff, C. (1991). Effects of improved water supply and sanitation on ascariasis, diarrhoea, dracunculiasis, hookworm infection, schistosomiasis, and trachoma. Bulletin oh the World Health Organization, 69(5), 609-21.

Galdo, V., \& Briceño, B. (2005, May). Evaluating the impact on child mortality of a water supply and sewerage expansion in Quito: Is water enough? (Working Paper No. 01/05). Washington, D.C.: Inter-American Development Bank. https://publications.iadb.org/en/evaluating-impact-child -mortality-water-supply-and-sewerage-expansion-quito-water-enough

Gamper-Rabindran, S., Khan, S., \& Timmins, C. (2007, September). The impact of piped water provision on infant mortality in Brazil: A quantile panel data approach (Research Paper No. 24). Economic Research Initiatives at Duke (ERID). http://ssrn.com/abstract $=1129044$

Greenstone, M., \& Hanna, R. (2014). Environmental regulations, air and water pollution, and infant mortality in India. American Economic Review, 104(10), 3038-3072. http://dx.doi.org/10.1257/aer.104.10.3038

Jalan, J., \& Ravallion, M. (2001, August). Does piped water reduce diarrhea for children in rural India? (Policy Research Working Paper No. 2664). Washington, DC: World Bank. http://documents.worldbank.org/curated/en/499051468750284213/

Does-piped-water-reduce-diarrhea-for-children-in-rural-India

Kassouf, A. L. (1995). Saneamento e educação: Bens substitutos ou complementares? [Sanitation and education: Substitute or complementary goods?] Pesquisa e Planejamento Econômico, 25(2), 359-382. http://ppe.ipea.gov.br/index.php/ppe/article/view/782

Kremer, M., Leino, J., Miguel, E., \& Zwane, A. P. (2010). Spring cleaning rural water impacts, valuation and institutions. The Quarterly Journal of Economics, 126(1), 145-205. http://dx.doi.org/10.1093/qje/qjq010

Kumar, S., \& Vollmer, S. (2013). Does access to improved sanitation reduce childhood diarrhea in rural India? Health Economics, 22, 410-427.

Lee, L., Rosenzweig, M., \& Pitt, M. (1997). The effects of improved nutrition, sanitation, and water quality on child health in high-mortality populations. Journal of Econometrics, 77, 209-235.

Lilford, R. J., Oyebode, O., Satterthwaite, D., Melendez-Torres, G. J., Chen, Y.-F., Mberu, B., ... Ezeh, A. (2017). Improving the health and welfare of people who live in slums. The Lancet, 389(10068), 559-570. http:// dx.doi.org/10.1016/S0140-6736(16)31848-7

Merrick, T. W. (1985). The effect of piped water on early childhood mortality in urban Brazil, 1970 to 1976. Demography, 22(1), 1-24.

Nijman, T., \& Verbeek, M. (1992). Nonresponse in panel data: The impact on estimates of a life cycle consumption function. Journal of Applied Econometrics, 7(3), 243-257. http://dx.doi.org/10.1002/jae.3950070303 
Sanders, J. W., Fuhrer, G. S., Johnson, M. D., \& Riddle, M. S. (2008). The epidemiological transition: The current status of infectious diseases in the developed world versus the developing world. Science Progress, 91(1), $1-38$.

Sastry, N., \& Burgard, S. (2005). The prevalence of diarrheal disease among Brazilian children: Trends and differentials from 1986 to 1996. Social Science \& Medicine, 60, 923-935.

Soares, R. R. (2007, May). Health and the evolution of welfare across Brazilian municipalities (Working Paper No. 13087). NBER. http://dx.doi.org/ $10.3386 / \mathrm{w} 13087$

Watson, T. (2006). Public health investments and the infant mortality gap: Evidence from federal sanitation interventions on U.S. Indian reservations. Journal of Public Economics, 90(8-9), 1537-1560. http://dx.doi.org/ 10.1016/j.jpubeco.2005.10.002 


\section{Appendix A Attrition Tests}

In this appendix, we describe the two tests of attrition used in the paper. The first is a modified version of the test used by Becketti, Gould, Lillard, and Welch (1988). In our model, the sample grows over the period from 2003 to 2010; thus, to verify if municipality records are related to their prior water and sewage indicators, we used a test that relates the health indicator in 2010 with sanitation indicators in the same year and a variable that is equal to the health indicator in 2010 if the municipality appears in any of the previous years and equal to 0 otherwise. In this test, we estimated the following model:

$$
\text { IndHealth }_{i, 2010}=\beta_{0}+\beta_{1} \text { IndWater }_{i, 2010}+\beta_{2} L_{i} \text { IndWater }_{i, 2010}+u_{i, 2010},
$$

where $L_{i}$ is equal to 1 if the municipality appeared in the sample in any previous period $(2003,2004,2005,2006,2007,2008$, and 2009). In this case, the significance of coefficient $\beta_{2}$ is tested. If attrition is completely random, this coefficient should be non-significant because the second variable does not add any new information to the regression. The second test was proposed by Nijman and Verbeek (1992) in which the fixed effects model is estimated and includes sanitation variables from one and two previous periods and binary variables that indicate if municipality i appeared in the previous periods:

$$
\begin{array}{r}
\text { IndHealth }_{i t}=\beta_{0}+\beta_{1} \text { IndWater }_{i t}+\beta_{2} \text { IndWater }_{i, t-1}+\beta_{3} \text { IndWater }_{i, t-2} \\
+\alpha \text { Controls }_{i t}+\eta_{1} s_{i, t-1}+\eta_{2} s_{i, t-2}+a_{i}+\delta_{t}+u_{i t},
\end{array}
$$

where $s_{i, t-1}$ is equal to 1 if the municipality appeared in the sample in period $t-1$ and equal to 0 otherwise. Similarly, $s_{i, t-2}$ is equal to 1 if the municipality appeared in the sample in period $t-2$ and equal to 0 otherwise. In this test, we examined the statistical significance of the coefficients associated with $s_{i, t-1}$ and $s_{i, t-2}$.

Tables A1 and A2 present the results for the tests of ? and Nijman and Verbeek (1992), respectively. The results in Table A1 indicate that attrition is not random and show that it is related to the population size and sewage collection in the previous period. The results of the second test confirm this result. In Table A2, at least one coefficient associated with $s_{i, t-1}$ and/or $s_{i, t-2}$ is significant in nearly all models. 


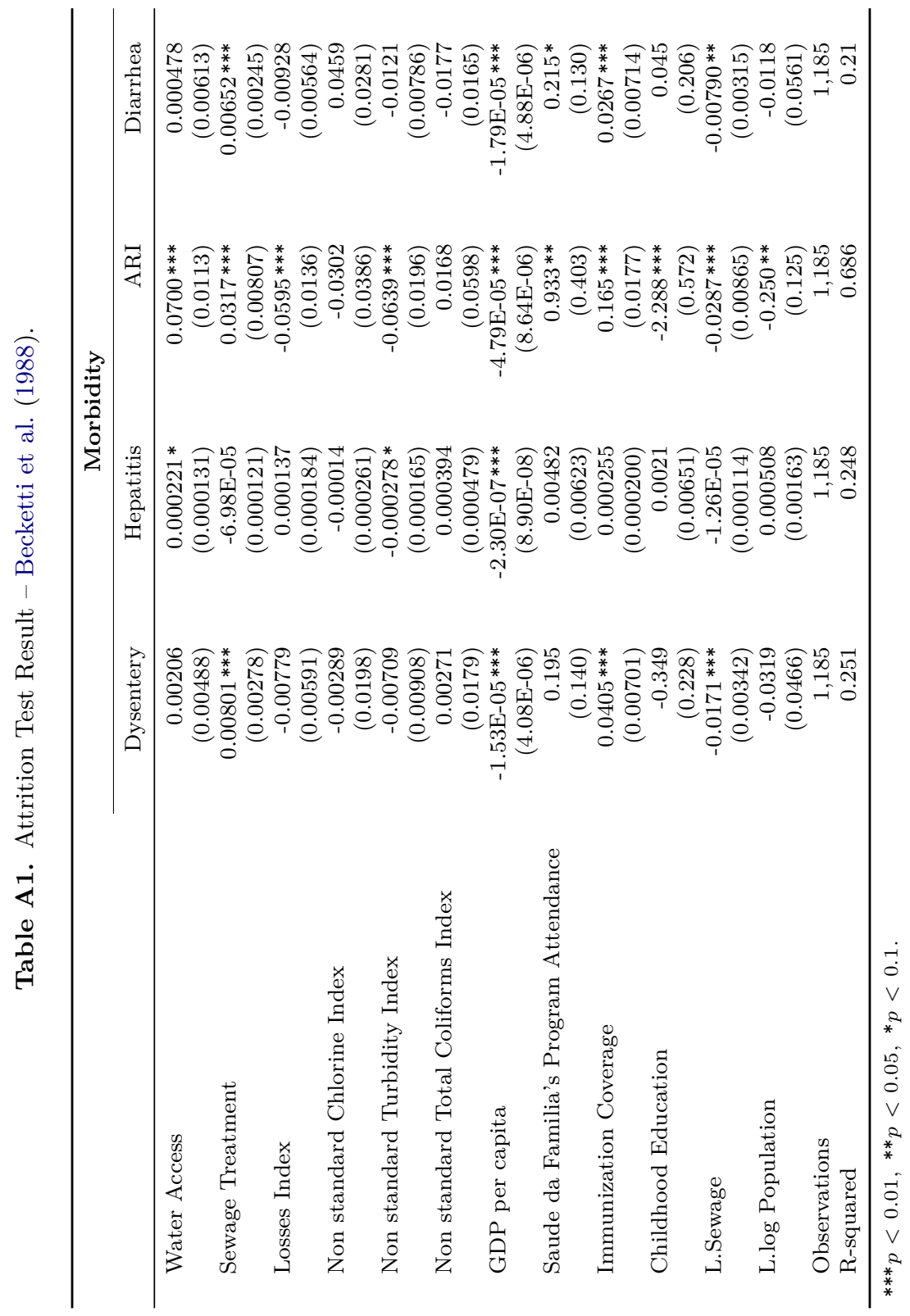




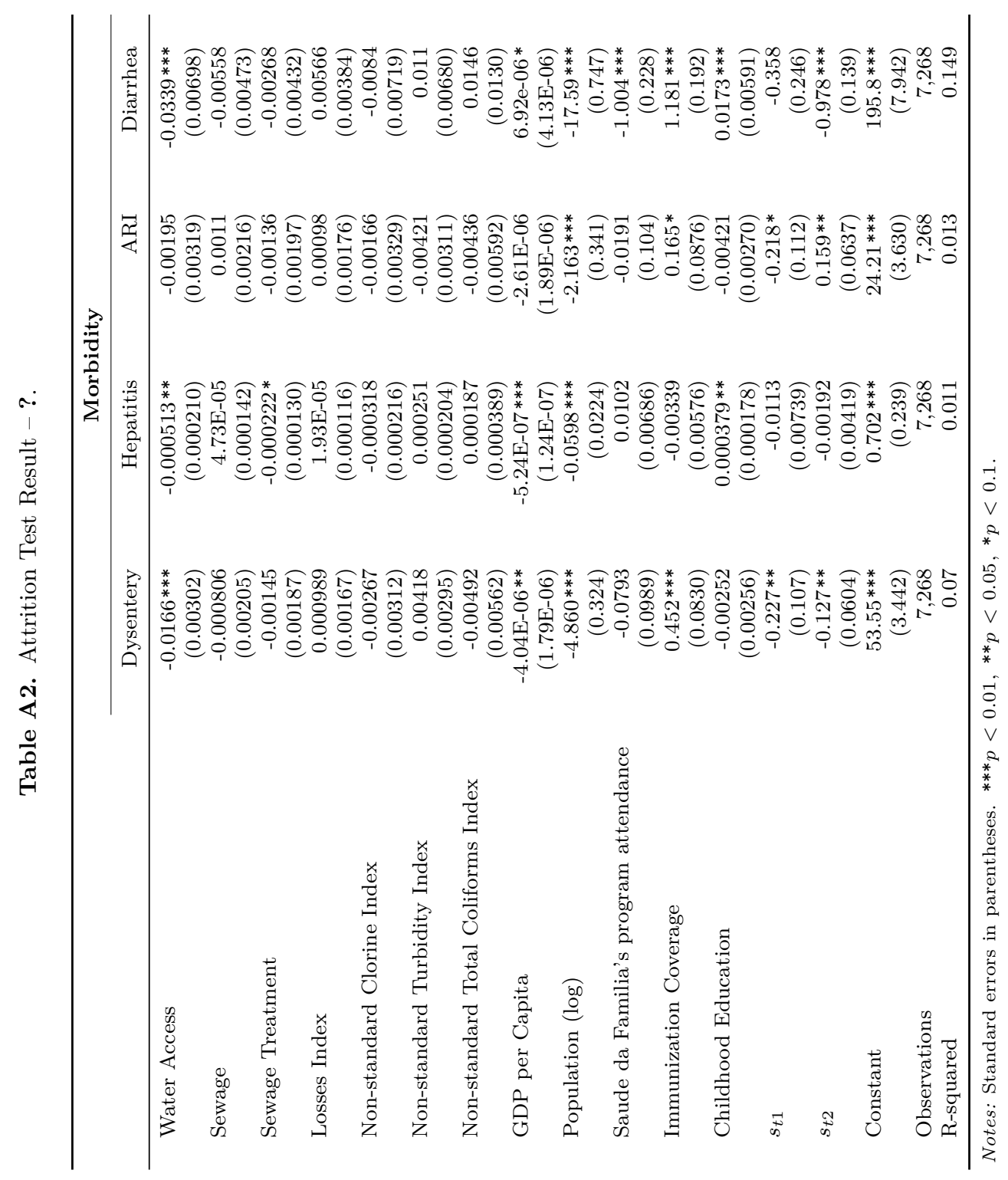




\section{Appendix B First Stage of Bias Correction}

In this appendix we present the results of the first step of the procedure used to correct for bias caused by attrition. In this step, we estimate the factors related to the probability of a municipality reporting information in each of the sample periods. Because our reference period is 2003, we have no information from previous years to predict the probability of the municipality reporting information in 2003. 


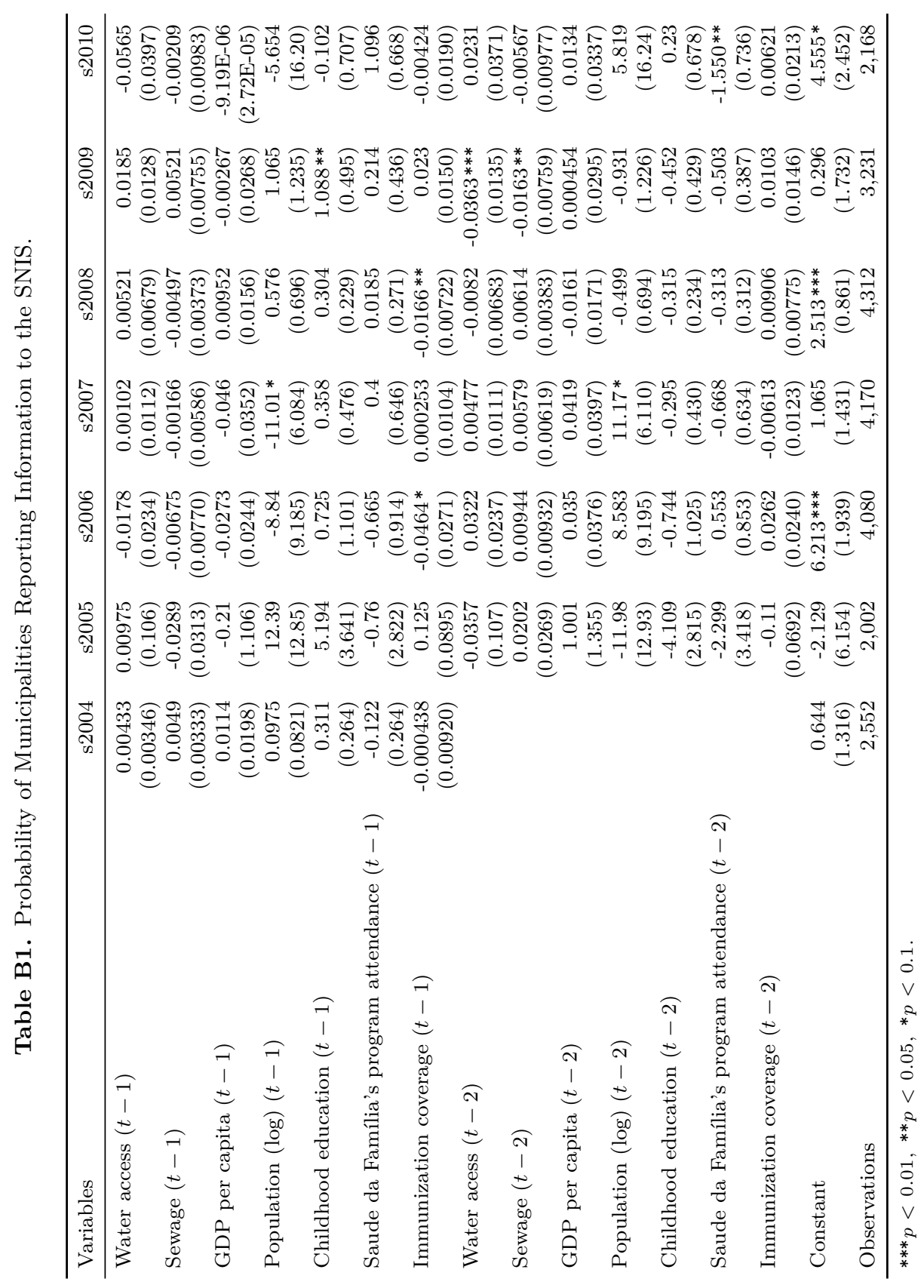




\section{Appendix C Fixed order models}

In this section, we present the results for the models used to investigate the epidemiological transition, and the municipalities are ordered according to their health indicators in 2010; this order is maintained over the years. The results of this new approach show the modest impact of sanitation indicators on health indicators. 


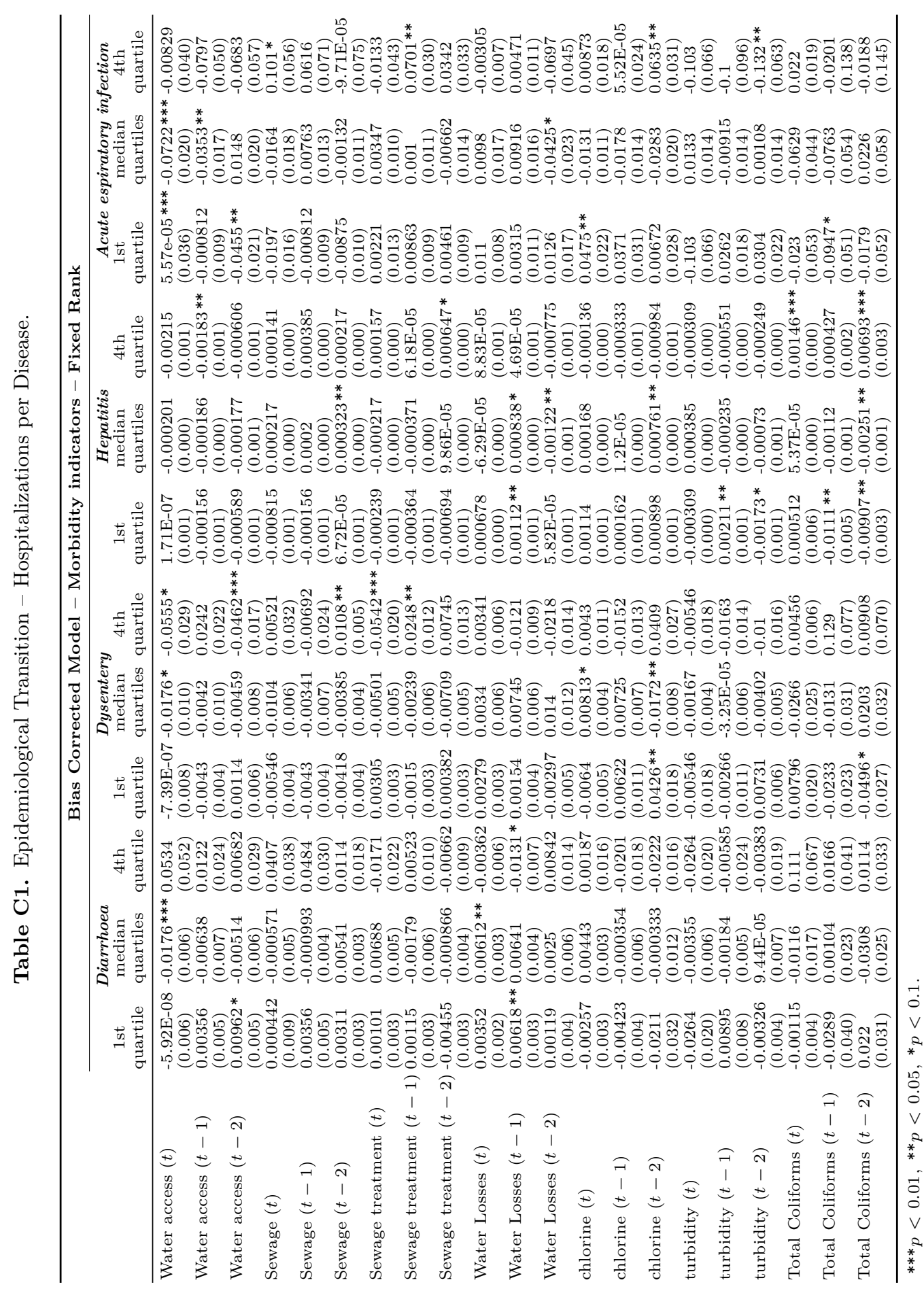

